\title{
Antibiotic resistant bacteria used as bioindicators of environmental pollution produced by tertiary treated sewage effluent
}

\author{
S. N. Al-Bahry ${ }^{1}$, I. Y. Mahmoud ${ }^{2} \&$ S. K. Al-Musharafi ${ }^{3}$ \\ ${ }^{1}$ Department of Biology, College of Science, \\ Sultan Qaboos University, Oman \\ ${ }^{2}$ Department of Biological Sciences and Chemistry, \\ University of Nizwa, Oman \\ ${ }^{3}$ Sur College of Applied Sciences, Oman
}

\begin{abstract}
Oman depends on recycling treated wastewater as a solution to overcome the limited water supply. However, the risk of reusing recycled sewage water in the environment and public health is a major concern. Tertiary sewage treated effluent (TSE) was evaluated microbiologically from three sewage treatment plants (STPs). Mainly, all TSE from the three plants contained coliform and Escherichia coli. Multiple antibiotic resistant bacteria (MARBs) were also present in the three plants and the TSE distribution lines used for irrigation. The faecal coliform counts in the tertiary treated wastewater samples from the storage tanks of the plants fell within the acceptable limits of the Omani standards for watering public parks and landscapes. Microbial counts from the distribution lines of all plants increased significantly farther from the main TSE storage tanks. Irrigated soil from TSE revealed the presence of MARBs. Some of the isolates from the plants and irrigated soils share similar antibiotic resistance patterns but significantly at lower values. In general most of the isolates were resistant to tetracycline and ampicillin followed by streptomycin and minocycline. Presence MARBs is a clear indication of TSE pollution and can be used for biomonitoring the environment. The present systems of STPs are unreliable for complete eradication of MARBs and pathogenic bacteria.

Keywords: sewage treated effluent, antibiotic resistant bacteria, pollution.
\end{abstract}




\section{Introduction}

The limited water resources in Oman have forced the authorities to recycle sewage effluents to overcome the limited water supply. The treated sewage effluent (TSE) in Oman is used for irrigating public parks, gardens, fruit crops and recharging aquifers. The access TSE is discharged to the coastal areas [1].

Microbiological analyses of TSE from the distribution lines indicated that $E$. coli exceeded the recommended concentrations permitted by the Omani standards for treated wastewater [1]. Several studies in Oman revealed the frequent occurrence of multiple resistant bacteria (MARB) from TSE to several antibiotics commonly used to treat infections in humans. Many of these microbes were found in different terrestrial and marine environment.

Although many MARBs are not considered primary pathogens, they remain a threat to public health due to possibilities of transmittance of resistance determinants to other microorganisms, especially human pathogens [2].

The presence of MARBs in environment may have emerged as a result of deliberate or accidental dumping of antibiotics leading to emergence of resistant bacteria and elimination or inhibition growth of susceptible bacteria [3]. The process of chlorination sewage effluents is supposed to eliminate both antibioticresistant and sensitive pathogens. However, the microbes may overcome chlorination and survive, causing public health issues. The rapid rise of MARBs is a major international concern particularly with the decline of new antibiotics available for treatment. In aquatic environment, bacterial resistance to antibiotics has received little attention. Bacterial faecal coliform has been use as an indicator of water contamination. MARBs from animals, such as poultry and fish, and contaminated food can be transported to humans by polluted water. Due to animal feeds containing antibiotics, poultry faeces are considered to be the main terrestrial source of MARBs and can be a threat to human health.

In sewage and aquatic environments, antibiotics become highly diluted and their detection becomes difficult. Thus, MARBs have been used in several studies as bio-indicators of contaminated effluents in marine and terrestrial environments. Contaminated effluents with MARBS were found in marine environment infecting fish and turtles. MARBs were also isolated from farms. Consumption of contaminated fish, eggs, and vegetables could lead to serious health problems [4-7]. Also, MARBS have been used for biomonitoring the environment exposed to polluted effluents [8].

The aims of this study are to evaluate the possible transmission of MARBs into the irrigated soil by the TSE and the viability of MARBs within the irrigation distribution system in Oman. Continuation usage of TSE might pose a danger to the human health, domestic animals, wild life and the environment.

\section{Materials and methods}

\subsection{Sample collection}

Three sewage treatment plants (STPs) were selected in Muscat, Oman. TSE generated form these plants are used for public usage including irrigation of 
public greeneries. The selected STPs were as follows: A = Industrial STP only, $\mathrm{B}=$ Industrial and residential STP, C=Hospital STP. Samples were collected weekly after chlorination over a period of two months. Samples were collected at STE storage tank and at distances 2, 4 and $6 \mathrm{~km}$ from the plant. Samples were collected and handled following the standard methods [9]. 1L sterile, labelled glass bottles were used to collect the effluent samples for microbial analysis [10]. Samples were preserved in a cooler at $10^{\circ} \mathrm{C}$ [9].

\subsection{Microbiological analysis}

Microbiological examinations used in this study included, enumeration of total bacteria as colony forming unit per $\mathrm{ml}(\mathrm{cfu} / \mathrm{ml})$ according to the Regulations for Wastewater Reuse and Discharge [1]. Also, the isolation of pathogens such as Salmonella, Shigella, Vibrio and Aeromonas species was conducted. Total bacterial count was processed by serial dilution using an automatic spiral platter (AutoPlate 4000, Spiral Biotech, USA). The instrument sucked the liquid from the tube $(50 \mu \mathrm{l} /$ plate) by a stylus into Petri-dish plates containing plate count agar. The plates were incubated for $24 \mathrm{hr}$ at $37{ }^{\circ} \mathrm{C}$. TSE samples were filtered using $0.4 \mu \mathrm{l}$ filter size and were placed on appropriate media for enumeration and isolation of coliforms, enterococci and E. coli. Samples that give positive results were further tested for the presence of human pathogens such as Salmonella, Vibrio, and others [9].

\subsection{Antibiotic resistance}

The isolates were exposed to 16 antibiotics following the standards disk diffusion method $[11,12]$. The isolates were grown separately on Luria Bertani broth (LB) for $4-6 \mathrm{~h}$ at $37^{\circ} \mathrm{C}$ to late logarithmic growth phase. Lawn cultures from (LB) were made on Muller Hinton agar (MHA) media with the use of sterile swabs. Sixteen antibiotics were dispensed using the antibiotic disk dispenser (Oxoid, UK) on MHA plate each containing bacterial lawn culture. The plates were incubated at $37^{\circ} \mathrm{C}$ for $24 \mathrm{~h}$. Inhibition zones were measured according to the international standards of disk diffusion method [12]. An E. coli strain (ATCC 25922) and Pseudomonas aeruginosa strain (ATCC 27853) lawn cultures were grown on MHA and were used as control to measure the inhibition zone diameter of the isolates according to the standard disk diffusion method of $[11,12]$.

\section{Results}

In the three localities, the heterotrophs were the most abundant followed by coliform, enterococci and E. coli (Figure 1). Overall, STP A showed the maximum concentration of heterotrophic bacteria. The most concentrated coliforms were in STP C. E. coli was the least enumerated microbe in all STPs.

As the distance increase from the STP plants in the three localities and the soil sites, there was a steady increase in microbial count (Figure 2). Colony forming unit $(\mathrm{cfu} / \mathrm{ml})$ from soil samples, was the lowest than cfu/ml from TSE samples. 




Figure 1: $\quad$ Microbial count from storage tank taken from three STPs.

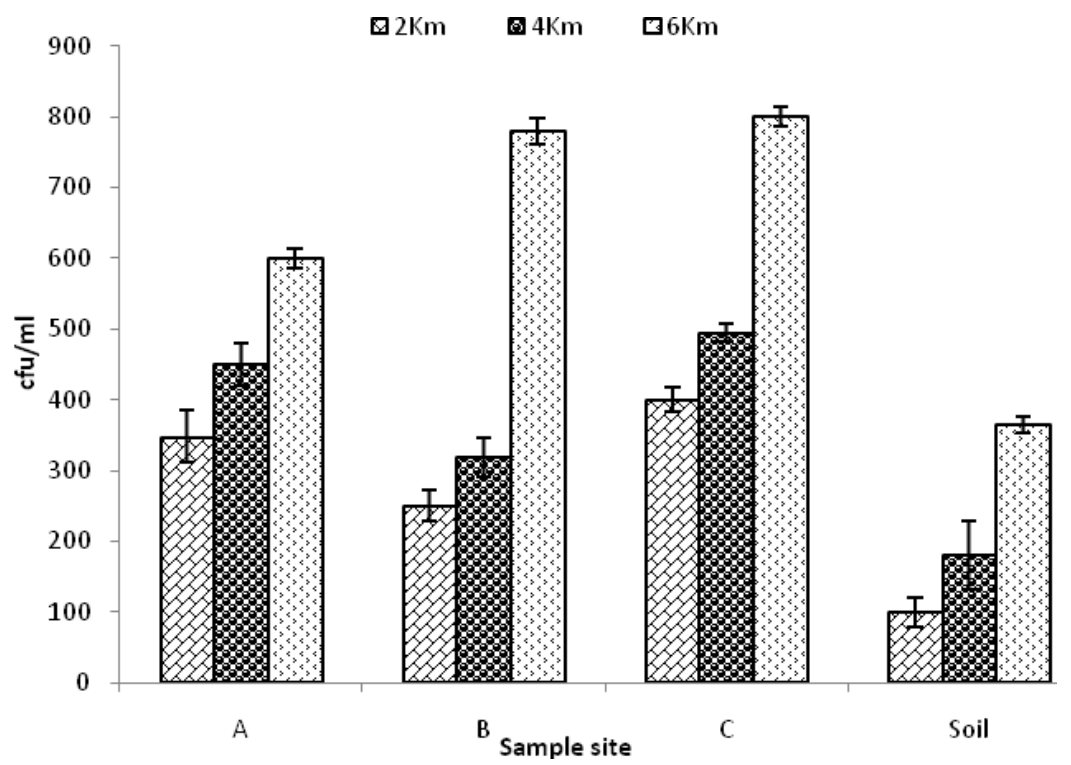

Figure 2: Microbial count taken from the three STPs at distances 2, 4 and $6 \mathrm{~km}$ and from soil in each locality. 
The frequency of the microbial isolates in the nine species showed wide range of concentration throughout the three regions and soil in the irrigation points (Figure 3). Pseudomonas was the most frequent isolate with the exception of STP A. Most of the pathogenic microbes were from STP C. The most frequent isolate was Pseudomonas followed by Aeromonas and Salmonella. On the other hand, Pasteurella was the most frequent isolate from STP A followed by Enterobacter and Aeromonas.

The frequency of antibiotic to resistant bacteria is shown in Figure 4 with a wide variation in the three localities with Amp, Min, Te and Tmp as the most frequent antibiotics. The most resistant bacteria to Te were in STP A and C. However, the highest percentage of Amp was in STP B.

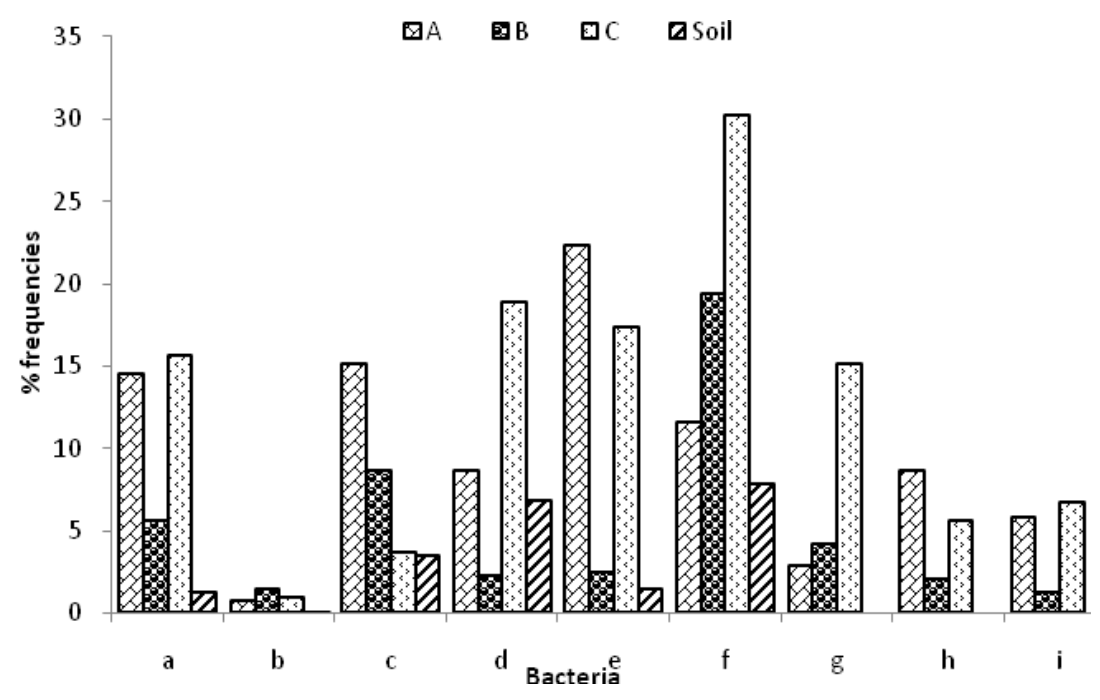

Figure 3: Microbial isolates from three STP localities and from soil in each locality. $\mathrm{a}=$ Aeromonas, $\mathrm{b}=E$. coli, $\mathrm{c}=$ Enterobacter, $\mathrm{d}=$ Klebsiella, $\mathrm{e}=$ Pasteurella, $\mathrm{f}=$ Pseudomonas, $\mathrm{g}=$ Salmonella, $\mathrm{h}=$ Shigella, $\mathrm{i}=$ Vibrio.

\section{Discussion}

In this investigation, the heterotrophic bacterial levels were highest followed by coliform, enterococci and E. coli. In addition, microbial count increased significantly away from the STPs suggesting that chlorination process is not sufficient enough to eradicate microbial contamination. Studies reported that disinfection process in sewage treatment plant results in greater reduction of microbial population exist in the treated wastewater [13]. However, it was revealed that low levels of bacteria remain viable after the chlorination $[4,5,8$, $14,15]$. 


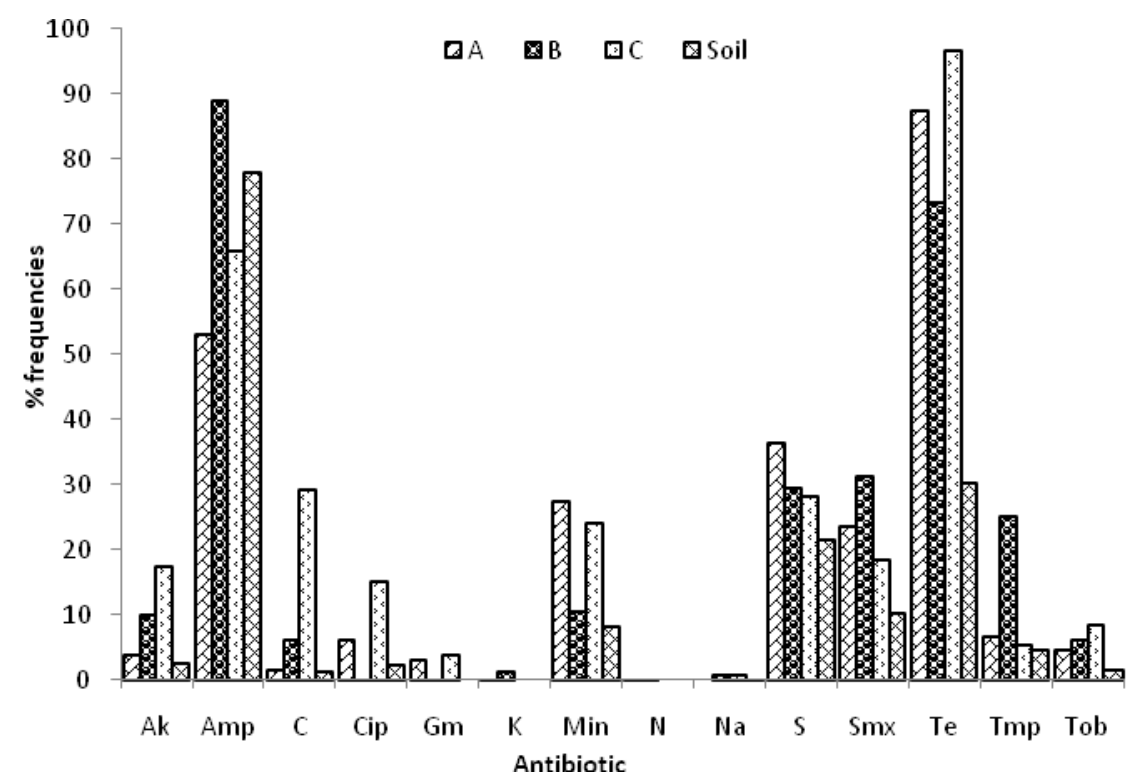

Figure 4: The frequency of resistant bacteria to antibiotics in the three localities and soil from each locality. $\mathrm{Ak}=$ amikacin, Amp=ampicillin, $\quad \mathrm{C}=$ chloramphenicol, $\quad \mathrm{Cip}=$ ciproflaxacin, $\mathrm{Gm}=$ gentamicin, $\mathrm{K}=$ kanamycin, Min=minocycline, $\mathrm{N}=$ neomycin, $\mathrm{Na}=$ nalidixic acid $\mathrm{Smx}=$ sulfamethoxazole, $\mathrm{S}=$ streptomycin, $\mathrm{Te}=$ tetracycline, $\mathrm{Tob}=$ tobramycin and $\mathrm{Tmp}=$ Trimethoprim.

This study was also designed to provide additional information about the reuse of recycled TSE and its potential to disseminate pathogenic bacteria and MARBs through the irrigation distribution systems. Pathogenic bacteria were isolated from the three STPs at various concentrations. Although it was expected that effluents will contain much more pathogenic microbes from hospital STP, the distribution of the pathogens showed no consistency relative to the nature of effluents. This indicates that the source of the treated effluents may not have a direct influence on the survival of pathogens in the three STPs.

In this investigation antibiotic resistant microbes were isolated from all sampling sites. The microbes that were resistant to more than one antibiotic were classified among the MARBs. The highest resistance was Te followed by Amp, Tmp and Min. The rest were at lower levels.

Antibiotic usage is considered to be the most important factor in promoting emergence and selection of antibiotic resistant microorganisms [16]. The wide spread use of various antibiotics as growth promoters for treating animal infections has led to the selection of antibiotic resistance allowing resistant strains to become dominant causing ecological problems [4, 5, 8, 14, 17]. The transfer of resistance genes in bacteria is favoured particularly by the presence of 
antibiotics at sub-therapeutic concentrations over a long period and can be a direct threat to public health [18-20].

Recent studies used polymerase chain reaction (PCR) in detection of resistant determinants and their distribution in the environment. Karami et al. [21] reported that $\mathrm{Tc}^{\mathrm{r}}$ is an attractive model for studying the ecology of antibiotic resistance. $\mathrm{Tc}^{\mathrm{r}}$ determinants were detected from different bacteria isolated from different environmental samples [22-24]. On the other hand, Al-Bahry et al. [5] used molecular techniques for detection of Amp resistant determinants for biomonitoring of marine habitats using multiplex PCR. Therefore, molecular techniques to detect resistant determinants are important methods for epidemiological studies of resistance. This technology provides important information about the transmission of resistant genes through bacterial populations [25].

It is clearly chlorination is not sufficient to eradicate pathogenic bacteria, specifically the MARBs, from the recycled water. New technologies are now in the process of experimentation, such as photo-catalysis and nanotechnology. Preliminary results show that these new technologies have efficiency in treatment of different water sources and hopefully will be widely implemented in the near future.

\section{Conclusions}

The data indicate that tertiary treatment of sewage effluents by chlorination is insufficient for total eradication of microbes, specifically MARBs. Microbial contamination levels tend to increase in the distribution lines with farther distance from the STP. In general, faecal coliform counts were within acceptable limits. The highest resistance to antibiotics from all samples was to ampicillin and tetracycline. Most of the microbes were multiple resistant to antibiotics. Highest levels of MARBs were isolated from hospital STP. The data suggest that MARBs can be used as bioindicators of pollution.

\section{References}

[1] Ministry of Regional Municipalities and Water Recourses (MEMWR). Regulation for wastewater reuse and discharge. Ministry of Regional Municipalities and Water Recourses. 1998.

[2] Van Der, D.K., Van, L., Heir, J., Schellart, J. and Heimstra, P. Maintaining quality without a disinfectant residuals. Amer. Water-Work Association Journal, 91, pp. 55-64, 1999.

[3] World Health Organization (WHO). Guidelines for drinking-water quality. Vol. III: Surveillance and Control of Community Supplies. Eastern mediterranean regional office. Regional center for environmental health activities (CEHA). Amman, Jordan, 1997.

[4] Al-Bahry, S.N., Mahmoud, I.Y., Al-Belushi, K.I., Elshafie, A.E., AlHarthy, A. and Bakheit, C.K., Coastal sewage discharge and its impact on fish with reference to antibiotic resistant enteric bacteria and enteric 
pathogens as bio-indicators of pollution. Chemosphere, 77, pp. 1534-1539, 2009.

[5] Al-Bahry, S.N., Mahmoud, I.Y., Elshafie, A.E., Al-Harthy, A., Al-Ghafri, S., Al-Amri, I. and Alkindi, A.Y., Bacterial flora and antibiotic resistance from eggs of green turtles Chelonia Mydas: an indication of polluted effluents. Marine Pollution Bulletin, 41, pp. 214-221, 2009.

[6] Al-Bahry, S.N., Mahmoud, I.Y., Al-Khaifi, A., Elshafie, A.E. and AlHarthy, A., Viability of multiple antibiotic resistant bacteria in distribution lines of treated sewage effluent used for irrigation. Water Science and Technology, 60, pp. 2939-2948, 2009c.

[7] Foti, M., Giacopello, C., Bottari, T., Fisichella, V., Rinaldo, D. and Mamminac, C. Antibiotic resistance of Gram negatives isolates from loggerhead sea turtles (Caretta caretta) in the central Mediterranean Sea. Marine Pollution Bulletin, 58, pp. 1363-366, 2009.

[8] Al-Bahry, S.N., Al-Zadjali, M.A., Mahmoud, I.Y. and Elshafie, A.E., Biomonitoring marine habitats in reference to antibiotic resistant bacteria and ampicillin resistance determinants from oviductal fluid of the nesting green sea turtle, Chelonia mydas. Chemosphere, 87, pp. 1308-1315, 2012.

[9] American Public Health Association/American Water Works Association/Water Environment Federation (APHA/AWWA/WEF). Standard Methods for the Examination of Water and Wastewater, $20^{\text {th }}$ edition. American Public Health Association/American Water Works Association/Water Environment Federation, Washington, DC. United Book Press Inc: Maryland, 1998.

[10] Carter, J.T., Rice, E .W. Butchberger, S.G. and Lee, Y. Relationship between level of hetrotrophin bacteria and water quality. Water Research, 34, pp. 1495-1502, 2000.

[11] Bauer, A.W., Kirby, W.M.M., Sherris, J.C. and Tuck, M. Antibiotics susceptibility testing by a standardized single disc method. American Journal of Clinical Pathology, 45, pp. 493-6. 1966.

[12] National Committee for Clinical Laboratory Standards, NCCLS. 1997.

[13] Tree, J.A., Adams, R.M. and Less, D.N. (). Chlorination of indicator bacteria and viruses in primary sewage effluent. Journal Applied Microbiology, 69, pp. 2038-2043, 2003.

[14] Al-Bahry, S.N., Mahmoud, I. Y., Al-Zadjali, M., Elshafie, A., Al-Harthy, A. and Al-Alawi, W., Antibiotic resistant bacteria as bio-indicator of polluted effluent in the green turtles, Chelonia mydas in Oman. Marine Environmental Research, 71, pp. 139-144, 2010.

[15] Berger, P. S., LeChevallier, M.W. and Reasoner, D. J. Control of biofilm growth in drinking water distribution systems. Environmental Protection Agency, 56, pp. 1513-1557, 1992.

[16] Van Den Bogaard, A.E., London, N., Driessen, C. and Stobberingh, E.E. Antibiotic resistance of feacal Escherichia coli in poultry farmers and poultry slaughterers. Journal of Antimicrobial and Chemotherapy, 47, pp. 763-771, 2001. 
[17] Chee-Sanford, J.C., Aminov, R.S., Krappac, I.J., Garrigues-Jeanjean, N. and Mackie, R.I. Occurrence and diversity of tetracycline resistance gene in lagoons and groundwater underlying two swine production facilities. Applied Environmental Microbiology, 67, pp. 1494-1502, 2001.

[18] Kümmerer, K. Antibiotics in the aquatic environment - A review - Part I. Chemosphere. 75, pp. 417-434. 2009a.

[19] Kümmerer, K. Antibiotics in the aquatic environment - A review - Part II. Chemosphere. 75, 435-441, 2009b.

[20] Miles, T.D, Mclaughlin, W. and Brown, P.D. Antimicrobial resistance of Escherichia coli isolates from broiler chickens and humans. $B M C$ Veterinary Research. 2: pp. 1-9, 2006.

[21] Karami, N., Nowrouzian, F., Adlerberth, I. and Wold, A.E. Tetracycline resistance in Escherichia coli and persistence in the infantile colonic microbiota. Antimicrobial Agents and Chemotherapy, 50, pp. 156-161, 2006.

[22] Aminov, R.I., Chee-Sanford, J.C., Garrigues, N., Teferedegne, B., Krapac, I.J., White, B.A. and Mackie, R.I., Development, validation, and application of PCR primers for detection of tetracycline efflux genes of Gram-negative bacteria. Applied and Environmental Microbiology, 68, pp. 1786-1793, 2002.

[23] Blake, D., Humphry, R., Scott, K., Hillman, K., Fenlon, D. and Low, J. Influence of tetracycline on tetracycline resistance and the carriage of tetracycline resistance genes within commensal Escherichia coli population. Journal of Applied Microbiology, 94, pp. 1087-1097, 2003.

[24] Bryan, A., Shapir, N. and Sadowsky, M. J. Frequency and distribution of tetracycline resistance genes in genetically diverse, nonselected, and nonclinical Escherichia coli strains isolated from diverse human and animal sources. Applied Environmental Microbiology, 70, pp. 2503-2507, 2004.

[25] Hartman, A.B, Essiet, I.I., Isenbarger, D.W . and Lindle, L.E. Epidemiology of tetracycline resistance determinants in Shigella spp. and enteroinvasive Escherichia coli: characterization and dissemination of tet (A)-1. Journal of Clinical Microbiology, 41, pp. 1023-1032, 2003. 